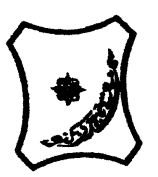

Bayero Journal of Pure and Applied Sciences, 10(1):215 - 218

ISSN 2006 - 6996

\title{
PREVALENCE OF ROTAVIRUS DIARRHOEA AMONG CHILDREN UNDER FIVE YEARS IN KADUNA STATE, NIGERIA
}

\author{
Aliyu, A.M ${ }^{1}$., Aminu, $M^{2}$., Ado, S.A ${ }^{2}$. and Jatau, E. $D^{2}$. \\ ${ }^{1}$ Department of Applied Science, C.S.T. Kaduna Polytechnic, Kaduna, Nigeria \\ ${ }^{2}$ Department of Microbiology, Faculty of Science, Ahmadu Bello University, Zaria, Nigeria \\ Correspondence author: aisha2zra@yahoo.com +2348035890640
}

\section{ABSTRACT}

Rotavirus (RV) is a major etiological agent of acute infantile gastroenteritis and is associated with $20 \%-25 \%$ of diarrhoea cases in infants. Nigeria continues to be among the first five countries with greatest number of $R V$ disease associated deaths per year. From September 2013-August 2014, 467 stool samples were collected from children under 5 years of age in Kaduna State, Nigeria and analysed for $R V$ antigen using ELISA. An overall $R V$ prevalence of $31.0 \%(143 / 467)$ was obtained with the infection occurring throughout the study period. Children from Kachia LGA had the highest prevalence of $53.8 \%$ (28/52), while children from Kagarko LGA had the lowest prevalence of $21.0 \%(10 / 74)$. The difference was significant $(P=0.019)$. Highest prevalence of $R V$ was recorded in March (75.0\%:3/4) and the least in July (11.5\%:3/26) with significant difference $(P=0.003)$. Female children had highest prevalence of $32.1 \%(79 / 246)$ compared to male children (29.9\%:66/221) with a non-significance difference $(P=0.530)$. Children within 25-36 months had the highest prevalence of 36.4\% (28/77), while children 49-60 months had the lowest prevalence of $17.6 \%$ (6/34) with no significant difference $(P=0.517)$. The difference observed was not significant $(P=0.477)$. The result showed no significant difference between the presence of $R V$ infection with vomiting, fever, dehydration $(P>0.05)$. The study has revealed that rotavirus remains an important cause of acute diarrhoea in children under five years in Kaduna State, Nigeria. Hence the need for the implemention of the vaccines into the childhood immunization programme in the country.

Key words: Prevalence, Rotavirus, Children, Kaduna State, Nigeria

\section{INTRODUCTION}

Rotaviruses are enteric pathogens causing acute, watery, dehydrating diarrhoea in various host species, including birds and mammals. Rotavirus is the cause for approximately 500,000 child deaths yearly, mainly in developing countries Rajendran and Kang (2014). The virus is the single most important cause of infectious, severe, dehydrating diarrhoea and death worldwide in children less than 5 years Pennap and Umoh (2010).

Rotavirus gastroenteritis is a mild to severe disease, with incubation period of about 1-2 days. The symptoms often starts with fever, nausea, and vomiting, followed by abdominal cramps and frequent watery diarrhea, which may last for 3-8 days. Infected children may also have a cough and runny nose. Rotaviruses are members of the family Reoviridae, nonenveloped and are characterized by the presence of 11 segment of double stranded RNA surrounded by 3 separate shells, the core, inner capsid and outer capsid Junaid et al.(2011).

The aim of the study was to determine the prevalence of rotavirus diarrhoea among children under 5 years in parts of Kaduna state.

\section{MATERIALS AND METHODS}

\section{Study Area}

The study was carried out in Kaduna state. Six LGAs which include Kachia, Kagarko, Soba, Sabon gari Chikun and Giwa were selected for the study.

Sample Collection and Analysis

A total of 467 stool samples were collected from children $0-5$ years of age across the six selected LGAs. All samples were transported in ice box to the Department of Microbiology, Faculty of Life Science, Ahmadu Bello University, Zaria and stored frozen at $-20^{\circ} \mathrm{C}$ until analyzed. 
Each $10 \%$ fecal suspension was screened for the presence of rotavirus antigens using commercially available enzyme immunoassay (EIA) kit (Premier Rotaclone Meridian Bioscience, Inc. USA). Data obtained was analyzed using statistical package for the social sciences (SPSS) version 21. Chisquare and odds ratio was used as test of association at $95 \%$ confidence interval with $\mathrm{p} \leq 0.05$ taken as statistically significant.

\section{RESULTS AND DISCUSSION}

Out of the 467 fecal samples screened for the presence of human rotavirus in children, $31.0 \%$ $(145 / 467)$ were positive for rotavirus antigens (Figure 1).

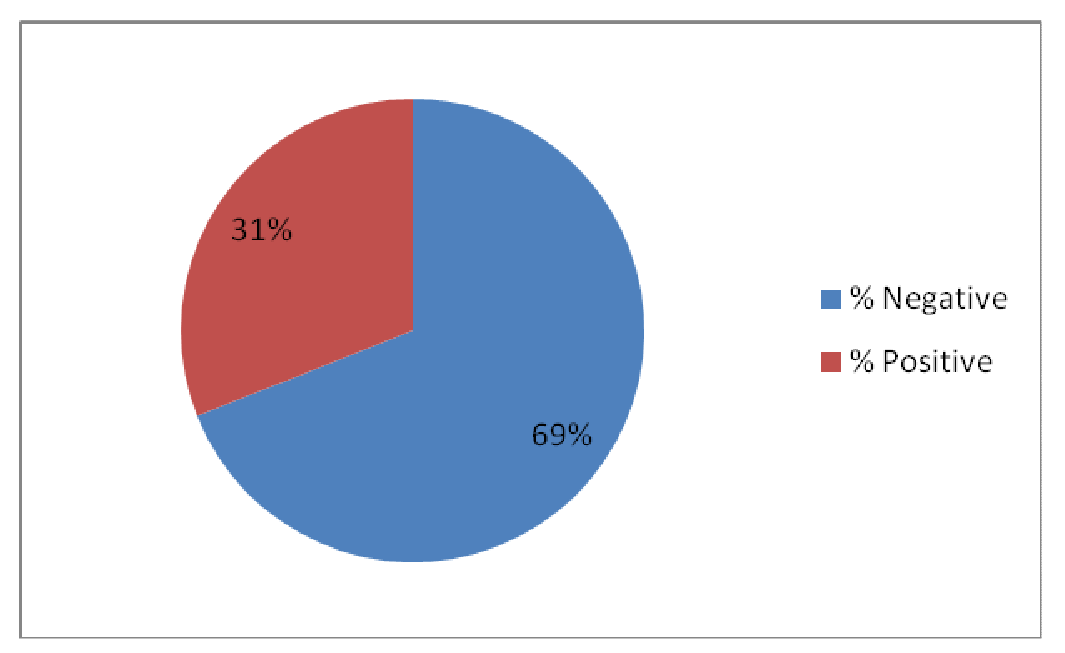

Figure1: Prevalence of Rotavirus among Children in Kaduna State, Nigeria

Rotavirus antigen was detected in children 0 5years in parts of Kaduna state with a prevalence of $31.0 \%$ in this study. The result agrees with $36.5 \%$ recorded in Kano Northern Nigeria WadaKura(2011). The finding also agrees with results in other African Countries and parts of the world.However, the prevalence is higher than those reported in Sokoto $25.5 \%$ (Alkali et al.,
2016) and North-western Nigeria 18.0\% (Aminu et al., 2010). This difference in prevalence could be due to the method and time of sample collection, sample storage, the season of sample collection and environmental factors such as population increase leading to over crowdiness as well as continued poor sanitary issues that include poor disposal of human waste.

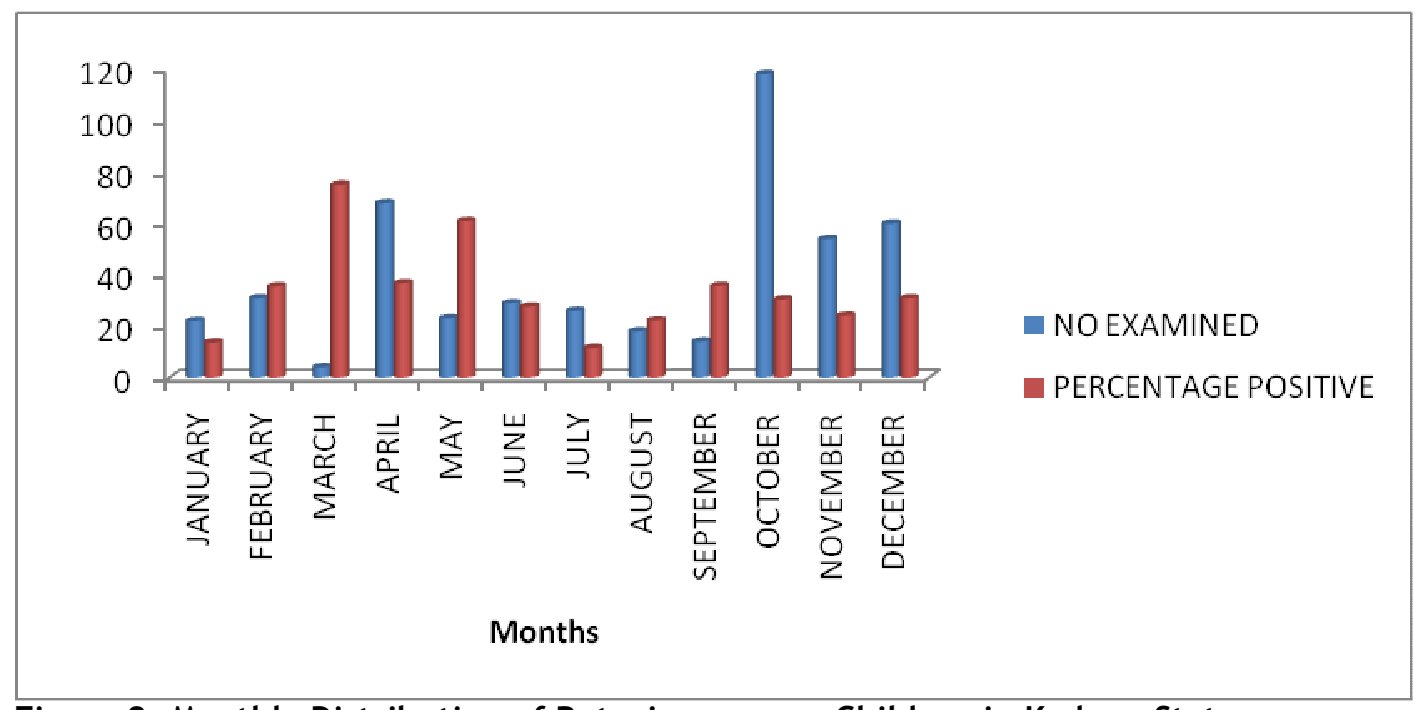

Figure 2: Monthly Distribution of Rotavirus among Children in Kaduna State 
Rotavirus was detected in children throughout the study period, with a slightly higher prevalence occurring during the dry season. This agrees with the findings of Aminu et al. (2010), and Wada- Kura (2011), who reported that the circulation of rotavirus might be lower during the wet season with slightly increased seasonal peaks during the cooler, dryer months from October to March in Africa especially West Africa including Nigeria. The higher prevalence of rotavirus infection in the dry season may be attributed to environmental factors with low relative humidity being the most important environmental factor.

Table 1: Age and Sex Distribution of Human Rotavirus Infection among Children in Parts of Kaduna State

\begin{tabular}{lccc}
\hline Parameter & No examined & No positive (\%) & p-value \\
\hline Age group (months) & 113 & $37(32.7)$ & \\
$0-12$ & 208 & $63(30.3)$ & \\
$13-24$ & 77 & $28(36.4)$ & 0.517 \\
$25-36$ & 35 & $11(31.4)$ & \\
$37-48$ & 34 & $6(17.6)$ & \\
$40-60$ & & & \\
\hline Sex & 221 & $66(29.9)$ & 0.536 \\
Male & 246 & $79(32.1)$ & \\
Female & & & \\
\hline
\end{tabular}

Rotavirus was recorded in all age groups 0-60 months. Although highest prevalence was recorded in age group 25-36 months, there was no statistically significant difference between age and the prevalence of rotavirus. This agrees with earlier findings in Nigeria by Wada-Kura (2011) and Paraguay Coluchi et al.(2002). The higher prevalence recorded among this age group (25-36 months) could be due to behavioral activities of children at this age, who tend to play outside with possibly feacally contaminated materials. Least prevalence was recorded in older children. This could be due to the fact that older children tend to become protected from severe form of rotavirus infection as a result of protection acquired from multiple reinfections Pennap and Umoh(2010).

There was no statistically significant difference between rotavirus infection and gender. This agrees with the findings of Pennap and Umoh (2010) and Wada-Kura (2011). Though in this study, females had a slightly higher prevalence than males. This difference could be due to chance, because at this age there is no difference in life styles between the boy and girl child.

Table 2: Observed Clinical Symptoms among Rotavirus Infected Children

\begin{tabular}{lccccc}
\hline Symptom & No tested & No positive (\%) & OR & Cl on OR & P-value \\
\hline Vomiting & & & & & \\
Yes & 178 & $52(29.2)$ & & & \\
No & 289 & $93(32.2)$ & 0.870 & $0.674-1.004$ & 0.501 \\
Fever & & & & & \\
Yes & 258 & $67(14.3)$ & 0.589 & $0.345-0.976$ & 0.008 \\
No & 209 & $78(37.3)$ & & & \\
Dehydration & & & & & \\
Absent & 218 & $69(31.7)$ & & & 0.691 \\
Mild & 183 & $55(30.1)$ & & \\
Severe & 66 & $21(31.8)$ & & & \\
\hline
\end{tabular}

There was no statistically significant association between fever, vomiting and dehydration with the prevalence of rotavirus infection. This contrast the finding of Pennap and Umoh (2010), who reported that the most common clinical features associated with rotavirus diarrhoea were fever and vomiting. Fever, vomiting and dehydration are factors usually associated with rotavirus infection in children. 
The lack of association between fever, vomiting and dehydration with rotavirus infection in this study can be explained by the fact that majority of the rotavirus positive children were older children above 12 months of age, with the rotavirus infection peaking among children 25-36 months. It could also be due to development of

\section{REFERENCES}

Alkali, B.R., Daneji, A.I., Magaji, A.A., Bilbis, L.S. and Bande, F. (2016). Molecular Characterization of Human Rotavirus from children with Diarrhoeal Disease in Sokoto State, Nigeria. Molecular Biology International, 2016: 1-9.

Aminu, M., Page, N.A., Ahmad, A.A., Umoh, J.U., Dewar, J., and Steele,A.D. (2010). Diversity of Rotavirus VP7 and VP4 Genotypes in Northwestern Nigeria. Journal of Infectious Diseases, 202(S1): S198-S204.

Coluchi, N., Munford, V., Manzur, J., Vazquez, C. and Escobar, M. (2002). Detection, Subgroup Specifity, and Genotype Diversity of Rotavirus Strain In Children with Acute Diarrhoea in Paraguay. Journal of Clinical Microbiology, 40(4): 1709-1714.

Junaid, S.A., Umeh, C., Olabode, A.O., and Banda, J.M. (2011).Incidence of Rotavirus immunity at this age group leading to sub clinical manifestation.

\section{CONCLUSION}

The study has revealed rotavirus remains an important cause of acute diarrhoea in children under five years in Kaduna State.

in Children with Gastroenteritis Attending Jos University Teaching Hospital, Nigeria. Virology Journal, 8(1): 233-238.

Pennap, G. and Umoh, J. (2010). The Prevalence of Group A Rotavirus Infection and Some Risk Factors in Pediatric Diarrhoea in Zaria, North Central Nigeria. African Journal ofMicrobiology Research, 4(14): 1532-1536.

Rajendran, P. and Kang, G. (2014). Molecular Epidemiology of Rotavirus in Children and Animals and Characterization of an unusual G10P[15] Strains Associated with Bovine Diarrhoea in South India. Vaccine, 32S: A89-A94.

Wada-Kura, A. (2011). Molecular Characterization of Rotaviruses Detected in Children Under the Age of Five Years with Diarrhoea in Kano State-Nigeria. An unpublished M.Sc research thesis submitted to the school of postgraduate studies, Ahmadu Bello University, Zaria. 